\title{
Trilhas e saberes compartilhados no feminismo no rural: entrevista com Verônica de Santana
}

Trails and Shared Knowledge in Feminism in the Rural: Interview with Verônica de Santana

Caminos y saberes compartidos en el feminismo rural: entrevista con Verônica Santana

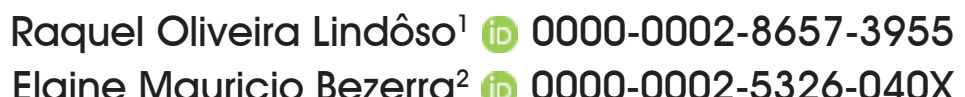
Elaine Mauricio Bezerra² ${ }^{\text {(i) }}$ 0000-0002-5326-040X
'Universidade Estadual de Campinas, Programa de Pós-Graduação em Ciências Sociais Campinas, SP, Brasil.13083-970 - ppgcs@ch.ufcg.edu.br

${ }^{2}$ Pesquisadora independente, Campina Grande, PB, Brasil. 58429-900
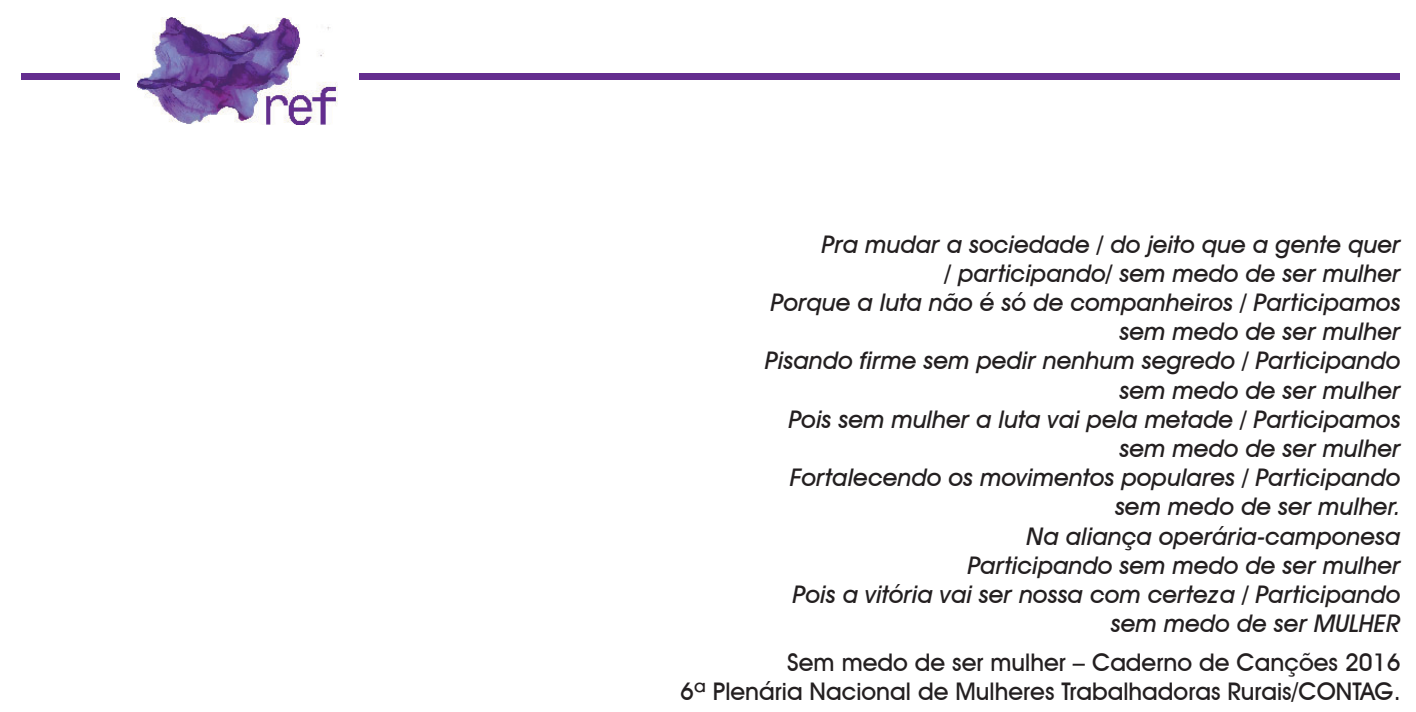

Verônica Santana é uma das principais lideranças feministas na atualidade, especialmente para a luta feminista construída na região do Nordeste brasileiro. A atuação política de Verônica Santana foca nas demandas das trabalhadoras rurais, tais como a diversidade de atividades produtivas no rural e a agroecologia. Verônica Santana é trabalhadora rural e assentada da reforma agrária no estado de Sergipe. Ela compôs a direção regional do Movimento da Trabalhadora Rural do Nordeste (MMTR-NE)' (há pesquisas acadêmicas que tratam da epistemologia do MMMTR-Ne, especialmente sobre debate acerca do feminismo no rural, como as de lasmim Araujo VIEIRA (2017) e Gabriela Monteiro ARAÚJO (2019)) entre os anos de 20082010. Em seguida, assumiu a secretaria executiva de 2011 a 2016 e fez parte da coordenação executiva na gestão de 2017 a 2019. O MMTR-NE surgiu na década de 1980 e está sediado na cidade de Caruaru, em Pernambuco. Atualmente, o movimento está organizado nos nove estados da região Nordeste.

A relação das autoras com Verônica Santana é longa, já que, assim como Verônica, somos mulheres nordestinas e feministas. Compartilhamos alguns espaços de militância com Verônica, que é para nós referência de luta e sabedoria. A trajetória de Verônica, e das mulheres 
do MMTR-NE, nos ensina que o feminismo é plural e que as mulheres rurais têm muito a nos ensinar sobre as estratégias de resistências e ressignificação do território. E são essas estratégias acumuladas ao longo do tempo que alimentam as elaborações do que as mulheres rurais nomeiam de feminismo no rural.

Nós entramos em contato com Verônica via whatsapp, objetivando convidá-la para conversar sobre a participação do MMTR-NE na construção e realização da Marcha das Margaridas, ${ }^{2}$ bem como conhecer o olhar do MMTR-NE sobre o lugar do patriarcado no recrudescimento do conservadorismo no Brasil e a resistência da luta feminista. Verônica, de maneira generosa, aceitou conversar conosco. A entrevista aconteceu na sede do MMTR-NE, numa tarde ensolarada de agosto de 2019, dias após a realização da Marcha. No transcorrer da conversa, que durou quase três horas, Verônica falou sobre a grandeza e desafio da Marcha das Margaridas nesse contexto atual, no qual os direitos e a vida das mulheres estão sob forte ameaça. A sede do MMTR-NE está localizada na cidade de Caruaru-PE, estrategicamente próxima da rodoviária, para facilitar o trânsito das mulheres, numa rua calma e silenciosa, recentemente asfaltada. A sede chama atenção pelas paredes externas e internas pintadas de rosa pink (ou "rosa cheguei", como costumeiramente se fala na região). O rosa é a cor oficial do MMTR-NE, presente nas bandeiras, camisas e nas saias volumosas e rodadas das mulheres rurais. Essa cor, frequentemente associada à fraqueza, ganha novos significados na luta corajosa e destemida das trabalhadoras rurais do Nordeste.

A entrevista está organizada em quatro fases, para além da introdução. A primeira busca revisitar a trajetória de Verônica Santana na reforma agrária até seu encontro com MMTR-NE e o feminismo. A segunda deteve-se na questão de como a atuação do movimento contribui para pensar o feminismo a partir do sujeito mulher trabalhadora rural, o que torna mais complexo o debate da práxis e epistemologia feminista. O terceiro ponto trouxe um debate sobre 0 patriarcado como uma categoria potente para pensar não apenas o machismo no Nordeste, mas, e sobretudo, como algo que está presente na ascensão recente do conservadorismo no Brasil. E, por fim, o quarto momento trata do protagonismo da luta feminista no enfrentamento ao conservadorismo, com destaque para a Marcha das Margaridas de 2019.

Raquel Lindôso (RL) e Elaine Bezerra (EB): Verônica, você poderia falar um pouco da sua origem e trajetória?

Verônica Santana (VS): Eu sou agricultora, assentada, agroecológica e moro no estado de Sergipe, num assentamento rural com minha família. Nesse assentamento, estão assentadas eu e mais minhas duas irmãs. Eu tenho um companheiro e três filhos e agora um neto. Tenho cinquenta e um anos, sou do sertão de Sergipe, mas moro nesse assentamento, que é na região sul de Sergipe, há vinte e nove anos. E esse assentamento em que eu moro é o primeiro assentamento dessa região, da região sul de Sergipe, então, foi a primeira ocupação de terra da região e o primeiro assentamento. E aí eu tenho um bocado de tempo na luta, né? Comecei muito, muito jovem, ainda adolescente nas pastorais, igrejas e grupo de jovens, ainda na década de oitenta. Essa região pertence a uma diocese, que é a diocese de Propriá, município que fica no São Francisco, às margens do rio São Francisco. E a diocese de Propriá compreende toda a região que a gente chama o baixo São Francisco, que é onde tem a foz do Rio São Francisco, subindo ao alto sertão. Então, em Sergipe, a luta pela terra vai se dá muito forte nessa região, a partir de luta de posseiros, tanto no baixo São Francisco como, também, no município de Porto da Folha, Poço Redondo. Teve um movimento muito intenso de fazendeiros, apoiado por um juiz e, nessa região, querer expulsar muitos posseiros das terras e de uma aldeia dos índios Xocó que fica numa ilha que é chamada ilha de São Pedro, vizinha à Fazenda Caiçara.

É nesse cenário, de várias lutas pela terra, perseguição - já que naquela época era muito forte essa coisa dos jagunços - que, no ano oitenta e cinco, mais ou menos, tem a primeira ocupação de terra organizada com o Movimento Sem Terra (MST). A ocupação é a Barra da Onça e muitas trabalhadoras e muitos trabalhadores dessa região participam dessa ocupação junto com

\footnotetext{
${ }^{2}$ A Marcha das Margaridas é uma mobilização das mulheres do campo, da floresta e das águas que se tornou parte da agenda do Movimento Sindical de Trabalhadores e Trabalhadoras Rurais (MSTTR). É organizada e realizada pela Confederação Nacional dos Trabalhadores Agricultores e Agricultoras Familiares (Contag), em parceria com diversas organizações e movimentos feministas e de mulheres do Brasil. A primeira edição da Marcha das Margaridas foi no ano de 2000 e, após essa ação, definiu-se que ela passaria a ser realizada de quatro em quatro anos e que teria um caráter formativo, de denúncia e de pressão social, assim como de proposição, diálogo e negociação com o Estado por políticas públicas. Ao todo, já foram realizadas seis edições da marcha nos anos de 2000,2003 , 2007, 201 1, 2015 e 2019. A Marcha das Margaridas de 2019 teve como lema "Margaridas na luta por um Brasil com soberania popular, democracia, justiça, igualdade e livre de violência". A marcha de 2019 foi muito especial por causa da aliança formada entre as margaridas e as mulheres indígenas, que marcharam com o lema "Lutar pelos nossos territórios é lutar pelo nosso direito à vida". Essa união entre agendas de luta em diálogo com os territórios é fundamental para ampliar e complexificar os feminismos baseados em experiências concretas de mulheres plurais.
} 
várias organizações, como a diocese, posseiros da região, Central Única dos Trabalhadores (CUT), os sindicatos rurais e o Partido dos Trabalhadores (PT). Outra coisa importante foram as lutas do enfrentamento à frente de emergência da seca, especialmente nesta década, visto que as secas eram bastante intensas.

A minha militância começa nesse período, nesse cenário e nesse lugar/território. Participo do MST e de várias ocupações em 1990 e, em março desse mesmo ano, a gente é então assentado/a nesse território. E a partir daí a luta se modifica. A gente passa um tempo ainda no MST e ajudando em outras ocupações, mas vai ser uma luta mais de resistir, de organizar o assentamento, de se organizar enquanto comunidade, depois, também, romper vários preconceitos e várias questões políticas neste município de Santa Luzia do Itanhy-SE/NE, que é o município em que eu vivo hoje. Santa Luzia do Itanhy é um município do litoral que foi muito forte na produção da cana, onde tinha grandes usinas, grandes engenhos de açúcar. Essa terra que a gente vive hoje era uma grande usina de açúcar, era uma grande produtora de cana e tinha um engenho nessa área em que a gente vive, muito marcado pela presença, lógico, do trabalho escravo, e é um município de negros e negras. É muito presente essa cultura negra e muito presente, também, a dominação dos coronéis brancos. Essa questão da submissão é muito forte nesse município e muita gente, também, quando a gente chega lá, tem medo da gente porque tem incentivo por parte dos políticos que a gente toma as terras, que a gente é ladrão de terra, que a gente é comunista e o povo tinha muito medo, e tinha aquela coisa das bandeiras vermelhas. A gente sofre muita perseguição do prefeito, do presidente do sindicato rural da época, que depois ele vai se redimir. Então, o processo de desmistificar isso e de construir alianças com outras comunidades, com outros assentamentos que começam a surgir, é muito a partir de nossa organização no assentamento. Depois, a gente organiza o PT nesse município, aí cria uma oposição, se junta à outra oposição. Enfim, hoje já faz trinta anos essa história.

Quando cheguei, eu tinha o meu filho mais velho, que tem trinta e três anos, mas, dos meus 3 filhos, eu tive dois lá nesse assentamento. Minha irmã chegou com a filha mais velha dela (tinha três meses), ainda no acampamento, e depois teve uma outra filha. Depois tem a primeira criança que nasce no assentamento que já está casada, que ainda vive no assentamento. E, a partir dessa vinda nossa dos vários acampamentos (teve gente que veio do sertão como eu, gente que veio do Centro-sul, gente que veio do baixo São Francisco e gente da região mesmo), essa mistura cultural, eu acho que foi uma coisa que nos favoreceu muito. Ela trouxe muitos conflitos, mas, ao mesmo tempo, foi muito boa para construir algo diferente. Então, o nosso assentamento é um território que ele começa a se formar a partir dessas várias culturas e tem um ar, eu acho, bem diferente de algumas outras comunidades nesta região.

RL e EB: Verônica, sobre o movimento de mulheres, o movimento feminista, e também o MMTR$\mathrm{NE}$, como se deram esses encontros?

VS: Nessa época, a nossa participação é muito forte a partir de outros movimentos que não o MMTR-NE. A luta das mulheres na luta pela terra é muito forte, mas não é uma coisa visibilizada. Nesses processos, minha irmã Madalena participou do primeiro encontro de formação do movimento e ela e uma outra companheira chamada lolanda, lá do sertão do Sergipe, também agricultora, participaram da fundação do MMTR-NE. Mas eu não integrava o movimento, assim, efetivamente, de forma orgânica.

A partir de noventa e sete, as mulheres vão se organizar enquanto movimento lá em Sergipe. Quando a gente chega no assentamento, tem as mulheres de Salgado, que é um outro município, que vão fazer parte desse assentamento e que estão participando do movimento, aí a gente se reaproxima e começa a participar. Em 2007, há uma discussão para mudança da direção da representação em Sergipe no Nordeste e as companheiras sugerem que seja eu ou minha irmã como uma das representantes. Eu sempre participei de toda a luta, mas, por muito tempo, tendo criança, três filhos pequenos...

Eu e minha irmã sempre participamos da luta cuidando das nossas crianças. Nós nos ajudávamos, uma ficava com o menino da outra. Ou, quando a gente ia junto, facilitava porque uma ajudava a cuidar dos filhos e filhas. Eu fui a primeira a parir, então, minha irmã ajudou muito a criar o mais velho, a cuidar. Depois ela teve as delas, enfim, sempre muito juntas e sempre parindo, e sempre parindo, e sempre tinha criança. Eu tive três, ela dois, então eram cinco crianças nesse processo de luta pela terra.

RL e EB: Antes do MMTR-NE você estava no MST e outras organizações de luta. Como era o debate das mulheres nessas organizações?

VS: Então, eu sempre participei de movimentos de igreja, partido político e assentamentos. Mas, qual é a questão? Nessas organizações se discutia essa perspectiva de gênero como uma coisa, assim, muito técnica: gênero é isso, homem é isso, mulher é isso... Essas diferenças, essas desigualdades são sociais... Nessa perspectiva, que ainda hoje em muitos lugares e muitos movimentos se discute, mas não tinha uma formação feminista. Você entender que existem 
essas diferenças, existem essas construções, mas, como é que você desvenda isso? Como é que você desconstrói?

Desde que eu nasci, desde jovem que eu tenho uma rebeldia, que eu não aceito isso que meu pai queria impor, que minha família queria. E eu nunca me conformei com isso e não queria isso para minha vida. Só porque eu nasci mulher eu não sou obrigada. Eu sempre fui feminista, só que eu não sabia que isso era ser feminista, então, é uma coisa da prática de vida, de se reconhecer no mundo e dizer: "olha, eu não aceito esses padrões ou esse papel que essa sociedade aqui, que minha família, ou seja lá quem for, está querendo impor. Eu quero construir o que eu quero ser". Vê muitas mulheres já idosas reconhecer que casou com o seu agressor... muito forte isso! Quando você sofria uma violência, a família obrigava o violentador a casar com você e você ia ter que viver o resto da sua vida com a pessoa que lhe violentou. Já pensou o que é isso? Um negócio terrível! Essa coisa do rural, de viver em comunidade, é uma coisa muito boa, mas traz muitos desafios para as mulheres. Então, a coisa do viver em comunidade, ter tudo em comum, fortalece as nossas resistências, mas é aquela coisa: todo mundo também está de olho na vida de todo mundo e você se sente muito sufocada, é muito cobrada pela própria comunidade para você ter um papel "de ser mulher". Depois eu vou entender e vou trazer isso para a minha militância, ou seja, entender que o feminismo vai dar as condições e as ferramentas de desconstrução dessas desigualdades.

Eu tenho um contato com o feminismo dentro do movimento e fora do movimento, mas é de uma forma que é meio difícil de falar (mas eu vou tentar falar). É como se o feminismo fosse uma coisa muito longe da nossa vida. É como se, para você ser feminista, você tem que acessar uma série de conhecimentos, sabe? Então, é o feminismo de uma mulher muito sabida falando para outras mulheres não tão sabidas, que somos nós (agricultoras). Aí, quando a gente olha para essa mulher, a gente não se enxerga nela e a gente tem dificuldade de se assumir como feminista.

O ano de 2012 (mais ou menos) vai ser bem marcante para nós. A gente está numa discussão: "Eu acho que eu sou uma feminista em construção!" Aí, uma companheira diz assim: "Ó, deixe de frescura que isso não existe! Ou você é, ou você não é!". Isso me cai a ficha e eu começo a refletir e fazer várias reflexões sobre o feminismo. A gente tem um jeito diferente de viver, de interpretar o feminismo, e a partir do nosso viver vamos aprofundando nossas referências e discussões. A gente vai também desmistificando muita coisa desse feminismo acadêmico, a partir, também, da nossa experiência de formação da escola feminista.

A gente vai ampliando a discussão do que é, por exemplo, ser uma mulher lésbica e nascer no rural. Enfim, a gente vai trazendo isso para a nossa vivência e a partir disso que a gente constrói o feminismo. Depois, a gente vai ampliando para outras questões, para as questões mesmo do nosso espaço, trazer a discussão da agroecologia e da afirmativa de que "sem feminismo não há Agroecologia!". Nós entendemos que a nossa vida fora do espaço não existe, então, é crucial discutir como as mulheres rurais e o nosso modo de vida têm a ver com o espaço que a gente ocupa. Pensar a casa, e, especialmente, o que está além da casa, como, por exemplo, ao redor da casa (quintais), o meio ambiente e a questão da água. Então, trazer essas questões da nossa vida para a roda é o que faz sentido para gente.

Por muito tempo, a sociedade vai ignorar a contribuição das mulheres na economia a partir do trabalho doméstico e a partir do trabalho dos cuidados. Tanto a economia tradicional como o marxismo não reconhecem isso como questões que são importantes para reprodução da vida, mas também tem o valor econômico na sociedade. Eu acho que muitas questões vão entrar nessa discussão, pra gente dizer o que é desse feminismo que a gente constrói, que a gente vive no rural. Quando se fala da questão de dupla jornada de trabalho, tripla jornada de trabalho, pra quem é da cidade, que trabalha fora, é fácil dizer: "Eu trabalho seis horas, oito horas, sei lá o quê. Chego em casa, eu trabalho mais não sei quantas horas...". No rural, é bem mais complexo.

RL e EB: Você encontra a Marcha Mundial de Mulheres no mesmo período que você encontra o MMTR-NE, ou seja, nos anos dois mil?

VS: Eu encontro a Marcha dentro do MMTR-NE. E a primeira grande ação que eu integro é a ação de $2010 .{ }^{3}$ Hoje sou militante da Marcha, para além do MMTR-NE. O MMTR-NE já construiu a primeira ação da Marcha em 2000, junto com a Marcha das Margaridas em Sergipe. A gente organizou as mulheres lá em Sergipe e eu comecei a participar mais, ter contato com as companheiras da Marcha Mundial e Marcha das Margaridas. A gente fez várias reuniões para

\footnotetext{
${ }^{3}$ A Marcha Mundial das Mulheres é um movimento feminista internacional que surge em 2000 como uma grande mobilização que reuniu mulheres do mundo todo em uma campanha contra a pobreza e a violência. No Brasil, o Movimento está presente em 20 estados, organizado em núcleos e comitês. A cada 5 anos, a Marcha Mundial das Mulheres realiza uma ação internacional para marcar seus processos de síntese e discussão da sua plataforma política. No ano de 2010, foi realizada a $3^{a}$ Ação Internacional que, no Brasil, foi marcada por uma marcha que percorreu o trajeto entre as cidades de Campinas e São Paulo durante 10 dias: de 8 e 18 de março.
} 
organizar as companheiras para ir para essa ação que foi uma ação de dez dias. Sergipe foi com um ônibus e tinha mulheres rurais, do MMTR, do movimento sindical, pescadoras, domésticas e sindicalistas urbanas nesse grupo. Em 2010, eu já era bem mais engajada e eu já estava muito mais profunda na discussão do feminismo. E nessa ação de 2010, eu ajudei a construir e participei muito ativamente dessa construção para dentro do MMTR e, a partir dessa época, eu fiquei integrada à Marcha Mundial.

Na nossa formação e de todo esse processo mais recente da nossa escola feminista, a gente vai bebendo em várias fontes. Então, muitos dos aprendizados na Marcha Mundial de Mulheres, principalmente, eu diria, assim, que o ponto-chave é o tema da economia e a compreensão de que maneira o patriarcado age nas nossas vidas. Como esse poder central do patriarca e de como ele se estrutura a partir das várias instituições: família, estado, igreja, mercado. A gente vai a partir dessa orientação, e dessa compreensão e dessa construção da Marcha Mundial de Mulheres, entender esse feminismo popular e militante. Mas, também, a gente vai ter outros pensamentos. Tem um histórico aqui da construção na escola feminista que é a partir da formação de educadores que tem o início no movimento que foi muito assessorado pelo SOS Corpo, ${ }^{4}$ trazendo essa questão do corpo e a perspectiva de uma escola como multiplicação da discussão feminista. A própria Cristina Buarque ${ }^{5}$ fez muito essa formação com as mulheres, de incentivar as mulheres a ler, a escrever. Que era importante elas lerem, elas escreverem, a questão do falar, ela foi muito importante nesse processo anterior à escola, dentro da formação do movimento. Aí as nossas construções, essa coisa de entender da Agroecologia e trazer essas reflexões. E é a partir disso mesmo, do que a gente vai participando, que a gente vai acumulando conhecimento.

RL e EB: O MMTR-NE produziu um filme ${ }^{6}$ sobre a trajetória da construção do feminismo no rural. Você pode falar um pouco como foi a experiência do filme? Por que ele surgiu? Quais foram as motivações?

VS: Quando as mulheres falam de conhecimento, elas estão falando de que tipo de conhecimento e de onde é que vem esse conhecimento? O que a academia faz, muitas das vezes e, na maioria das vezes, é sistematizar o conhecimento produzido por outras pessoas. $\mathrm{E}$ muitas das companheiras rurais que constroem muito conhecimento não são reconhecidas. $O$ filme é isso de reconhecer, de nos reconhecer, de reconhecer as nossas mulheres também como intelectuais e como referências.

É um pouco de fazer justiça para com essas mulheres. Ivanete Almeida, por exemplo, tem muitos livros escritos, e tem tantas outras como Maria da Penha da Paraíba, Margarida Alves, Dona Dijé quebradeira de coco do Maranhão, que morreu em setembro do ano passado. E Dona Josefa da Guia (dona Zefa), quilombola de Sergipe que faz músicas maravilhosas. Dona Faraíldes é de Sergipe e, recentemente, mas já tem tipo uns dois anos, aparece no vídeo que a $\mathrm{Cáritas}^{7}$ lançou, chamado Sem medo de ser mulher. ${ }^{8}$ A Nazaré Flor, que era da direção do Movimento [MMTR] e faleceu em dois mil e sete. A maioria das músicas que a gente canta no Movimento é de Nazaré. E eu vejo muita filosofia nessas mulheres, vejo demais! E, na verdade, essas mulheres são muito boas porque me inspiram também.

Portanto, o vídeo vem para dar conta dessa sistematização. Mas vem para uma questão antes: de nos desafiar a ser essas que sistematizam o nosso conhecimento. O vídeo tem essa proposta, de falar de nós por nós, nós falando de nós e não alguém falando da gente. Sistematizar esse conhecimento tem muitos desafios. Tem os desafios de domínio das ferramentas, da escrita, da leitura. E, quando ele vai para o audiovisual, então, ele é muito mais desafiador. O filme, ele é, também, a partir de uma inspiração de uma experiência anterior: a gente tinha um projeto e tinha uma vontade de sistematizar experiências agroecológicas das mulheres. Aí, a gente se desafiou a fazer essa sistematização, nós mesmas. A gente fez uma oficina pra isso no sertão de Alagoas, trazendo mulheres dos nove estados em 2012.

A metodologia do vídeo era que a gente pudesse sistematizar uma experiência de cada estado e a gente acabou sistematizando doze experiências. Fez essa oficina e todo mundo tinha que voltar para o seu estado e repetir, sistematizar lá. Com a exceção dessa, que foi feita a oficina, todas as outras [experiências] foram nós que fizemos esses boletins, ou seja, porque a gente, então, viu como é que fazia, como era que tirava foto e quais as informações eram importantes sobre o local e a experiência. Tudo isso a gente aprendeu, reproduziu e fez. Ficou bem legal os boletins! Depois, a gente fez um outro sobre experiência de Programa de Aquisição de Alimentos

\footnotetext{
${ }^{4}$ O SOS Corpo - Instituto Feminista para a Democracia - é uma organização feminista não governamental (ONG), fundada em 1981 e sediada na cidade de Recife-PE.

${ }^{5}$ Cristina Buarque é economista e antropóloga. Foi Secretária de Estado da Secretaria da Mulher de Pernambuco e atualmente é pesquisadora da Fundação Joaquim Nabuco.

${ }^{6}$ O filme encontra-se disponível na plataforma YouTube noendereço: https://www.youtube.com/watch? $\mathrm{v}=\mathrm{PQkIWTlyJc4}$.

${ }^{7}$ A Cáritas Brasileira é uma organização da sociedade civil que visa à defesa dos direitos humanos, da segurança alimentar e do desenvolvimento sustentável solidário.

${ }^{8}$ Filme produzido pela Cáritas Regional Nordeste 3.
} 
(PAA), que é do programa de doação simultânea. A gente sistematizou essas experiências e não teve dinheiro para publicar, para fazer impressão e tudo mais. Quando Heloíse ${ }^{9}$ veio e começou a participar de umas atividades com a gente. E assim a ideia do filme começou a nascer. "Quem vai aparecer no filme? Essas e essas pessoas. Quem vai filmar? Quem vai tomar conta do som?". E a gente foi praticar e depois o povo foi para cada lugar fazer as filmagens tudo. Das filmagens do filme, só tem de Heloíse as [imagens] da Marcha [das Margaridas], mas todas as outras cenas são nossas e a gente tem isso na memória.

Da oficina e as filmagens de cada estado, a gente tem em torno de cento e cinquenta horas que depois sofreram edição. O próprio nome do filme foi feito dessa forma, todo mundo deu sugestão e, no fim, ficou: Mulheres Rurais em Movimento. Toda construção foi coletiva.

RL e EB: Tem uma coisa no filme que você diz que o feminismo rural traz essa diversidade do que é ser rural. Ou seja, é ser agricultora, artesã, ser quilombola...

VS: Primeiro, eu tenho uma dificuldade enorme de ter a necessidade de nomear. Tem momentos e tem coisas que eu acho superimportante nomear, mas, nesse caso, eu acho que a gente está construindo muita coisa ainda e se não é uma fala coletiva, eu acho que eu não devo dizêla. Então, "a gente está construindo um feminismo rural", isso eu digo tranquilo. Agora, você dizer "esse é o feminismo rural" é como se você tivesse impondo um jeito. Não quero que a gente tenha um modelo: "isso aqui é feminismo rural". Eu acho que a gente está construindo um feminismo diferente no rural, mas não quero dizer que é a única forma, mas quero dizer que, no MMTR, a gente tem uma forma.

A gente vai trazer muito fortemente o sujeito mulher. Quando eu digo, no filme, "nós somos um movimento auto-organizado de mulheres no rural, nós não somos um movimento rural, somos um movimento de mulheres no rural", ou seja, o que está colocando em primeiro são as mulheres. Nós somos um movimento de mulheres que tem uma perspectiva agroecológica.

O Movimento é muito diverso, realmente, e ele assume isso muito fortemente em 2012, a partir de uma discussão que a gente fez aqui, numa assembleia. Esses são pontos que eu acho que marcam muito. De que nós somos um movimento diverso, que, na verdade, a mulher rural, ela não existe. Não existe uma categoria única de mulher. Isso eu tenho aprendido muito e a gente tem feito isso no movimento. Nós mulheres não somos iguais e nós temos muitas diferenças entre nós, de forma que o modo de se organizar, de pensar, não vai servir de um jeito só para todo mundo. E no rural é igual. Nós temos mulheres no rural que, por exemplo, nós somos um movimento do Nordeste e o Nordeste não é só semiárido.

Então, nós temos mulheres que são do semiárido, tem mulheres que não são do semiárido, tem mulheres brancas, muito poucas brancas, por sinal, que no Nordeste a maioria é preto mesmo, as mulheres são pescadoras, tem mulheres que são agricultoras, tem mulheres que têm terra, tem mulheres que não têm terra, são extrativistas, tem mulheres que são casadas com homem, tem mulheres que são casadas com mulher. O filme traz isso, ou seja, não existe "A mulher!". São várias. Isso foi muito importante para o movimento.

Quando eu digo que, para o movimento, o mais importante são as mulheres, tem muito a ver com isso, com essa metodologia, de a gente se reconhecer enquanto sujeito político, mas, também, dessas várias dimensões. Isso é muito importante para acolher as mulheres. É muito importante a gente criar esse sujeito coletivo, mas isso, na verdade, é real na vida das mulheres do Nordeste. O Nordeste não é uma coisa só.

Olha Brasilia está florida Estão chegando as decididas Olha Brasília está florida É o querer, é o querer das Margaridas Somos de todos os novelos De todo tipo de cabelo Grandes, miúdas, bem erguidas Somos nós as Margaridas Nós que vem sempre suando Este país alimentando Temos aqui para relembrar Este país tem que mudar!

O Canto das Margaridas.

RL e EB: Verônica, você pode falar um pouco de como foi a organização da última Marcha das Margaridas?

VS: A Marcha de 2019 foi bem diferente e foi bem mais difícil de organizar, de mobilizar as mulheres e de garantir as condições. Quando a gente começou a discussão, ainda antes da eleição, a gente começou a fazer os processos de reunião, de oficina para construção da Marcha no início de 2018. A gente queria lançar a Marcha em março de 2018 e fizemos um primeiro

${ }^{9}$ Héloïse Prévost é codiretora do longa-metragem Mulheres Rurais em Movimento. 
caderno. Foi se avaliando várias questões conjunturais para aquele momento e realmente era um momento do crescimento de tudo isso que a gente está vivendo, as consequências do golpe e tudo mais. Mas a gente tinha ainda várias esperanças e perspectivas, mas quando chegou em agosto, a gente já estava jogando com o que é que ia ser o Brasil em 2019, sendo um projeto político de direita.

A questão era assim: "Por que marchar?". A gente se fazia a pergunta e ia responder porque marchar e como marchar nos vários cenários. Fomos aprofundando essa construção e construindo a discussão política de como seria e ao mesmo tempo fazendo várias oficinas e pensando: Qual seria esse nosso documento para manifestar isso na sociedade? Aí a gente disse: então vamos construir os cadernos dos eixos temáticos para preparar as discussões. $\mathrm{E}$, nesse sentido, a gente avançou muito, pegando o acúmulo do que foram já as cinco Marchas anteriores. Porque a Marcha das Margaridas tem um histórico a partir do lema, dos documentos e ela vai acumulando uma discussão. A gente trouxe uma discussão bem bacana sobre autodeterminação dos povos, sobre a educação e educação não racista, trouxe coisas novas sobre a questão do racismo, sobre soberania energética e sobre orientação sexual também. Quando houve o resultado da eleição e do que estava acontecendo, ${ }^{10}$ então começou a discussão de como seria o formato da marcha. Porque a marcha sempre tinha uma pauta, a gente fazia as discussões e os cadernos que serviam de base para as discussões nos territórios. Depois, a partir dessas discussões, se propunha uma pauta. Essa pauta é uma pauta intensa, mas dentro dessa pauta a gente tirava prioridades que entregava para o governo antes da Marcha e o governo dava resposta na Marcha das Margaridas. Esse diálogo se deu até 2015. [Diante da eleição de Jair Bolsonaro], mesmo antes da posse, as Margaridas fizeram a leitura de que não havia condição de negociar com esse governo. Um governo que só retira direito, um governo que tem um pensamento muito lógico, muito claro sobre as mulheres, sobre os rurais, sobre o Nordeste, sobretudo, sobre os modos de vida nosso e de defesa dos territórios, nada sobre a previdência. E um governo que acaba com tudo e cria um ministério da família e coloca uma mulher que não dialoga nada com o movimento de mulheres.

A gente [O MMTR-NE] é contra esse modelo de família e aí você chega a um disparate de criar um ministério, uma política pública para garantir esse modelo de família. Então, esse ministério é uma afronta contra os movimentos de mulheres e contra aquilo que a gente tem construído dessa perspectiva de pensar que as pessoas podem ter vários modelos de famílias. Essa foi uma avaliação bem forte de que a gente corria o risco, inclusive, de ser recebida por esse ministério, por essa mulher, se a gente se propusesse a negociar com esse governo. Então, esse governo não tinha nada para a gente negociar e essa postura de governo em relação às mulheres com esse ministério - a gente não quer diálogo, a gente não concorda. A gente vai marchar, vai ocupar Brasília, mas a gente não negocia com governo. Então, a gente decidiu construir uma plataforma política ao invés de uma pauta, que também foi lançada na Marcha das Margaridas a partir dos acúmulos da discussão dos vários encontros.

Uma primeira diferença da construção dessa Marcha de 2019 foi: construir as condições para a marcha. O único recurso que a marcha nacional mobilizou foi da campanha virtual e da venda das rifas. Essa Marcha foi construída sobre muitos sacrifícios e a estrutura dela foi bem no mínimo mesmo. Mas, no final, houve comida e lugar para todo mundo. Conseguimos quatro ônibus, em Sergipe pulou de cinco para dezessete ônibus, Maranhão foi oitenta ônibus. O Maranhão foi o estado de maior adesão. Você sabe o que é oitenta ônibus, só de um estado? E a Marcha foi ganhando uma força. A gente ainda está nessa coisa de entender o que foi essa Marcha. Estavam as mulheres querendo dar resposta mesmo, querendo ocupar, querendo dizer que não concordam com nada disso que está acontecendo. Isso é muito importante, isso é uma força. As mulheres sabiam por que estavam marchando, sabiam, por que se preparam, sabiam por que já têm um acúmulo dessa Marcha. Mas, também, as mulheres estão fazendo a leitura a partir dos seus territórios, do que está acontecendo. Então, foi belíssima a Marcha. É sempre um momento muito forte da Marcha, eu gosto muito do processo de organização.

RL e EB: E como você analisa a atualidade do patriarcado nesse contexto de eleição de Jair Bolsonaro?

VS: Acho que tem duas coisas importantes: o patriarcado e o racismo muito fortemente atuantes. O patriarcado, principalmente, por essa coisa de não reconhecer as mulheres como sujeito político. Pegando o exemplo da política, as mulheres que ocupam espaço político aqui são as mulheres herdeiras políticas. É muito difícil, com raras exceções, de mulheres se firmarem na política. Isso é reflexo do patriarcado.

Uma coisa muito forte aqui no Nordeste é a questão do racismo. O racismo enquanto cor negra, como racismo enquanto região. Então, eu acho que essas duas questões para nós são centrais. Eu vi uma fala que afirmava: "a prisão do Lula é racista". Eu disse: "pronto, é isso!". A prisão do

${ }^{10}$ Refere-se à eleição de Jair Bolsonaro (sem partido), que tomou posse em janeiro de 2019. 
Lula é racista! Da gente ampliar essa questão do racismo para a questão da formação do nosso território enquanto Nordeste. E esse território nosso, ele é um território negro, ele é um território que é visto por outras regiões, a partir desse território racializado.

Nós somos um território racializado. Mesmo que você saia da questão negra, você vai carregar isso quando você chegar num lugar e dizer que é nordestino. Como estão dizendo: "é Paraíba!", entende? Você vai carregar essa carga de preconceito. Você ser do Nordeste é visto lá fora como: "Ah, eu sou branca!". Não! Você carrega essa coisa de ser uma região raceada." Isso não está explícito na mídia e em outros estudos, mas essa região é onde tem a característica mais forte da cultura africana. Tem outro lugar igual ao Nordeste? Não tem. Então, eu acho que a questão do racismo e a questão do patriarcado aqui, pra nós, elas têm leituras diferentes de leituras lá fora. Pra nós, isso faz muito sentido, discutir patriarcado, discutir o racismo, pra além dessa questão de classe. Porque eu acho que é muito, muito, muito importante pra nós.

Tem uma coisa que o feminismo mostra é que quando há grandes crises, a vida das mulheres é fortemente impactada. Então, tem uma pauta moralista terrível com esse governo e que ele está conseguindo se manter no poder muito agarrado nessa pauta moralista. Se você observar, sempre tem uma grande polêmica que vem junto com uma pauta moralista.

Então, no alvo dessa pauta moralista e de domínio das pessoas, é central ter o controle da vida das mulheres. É preciso dominar as mulheres: desde nos matar, até nos colocar para dentro de casa, nos colocar em situação de pobreza e muitas mulheres em situação de pobreza extrema. Quando você pensa sobre todos esses retrocessos, todos esses cortes dos orçamentos, todas essas medidas, elas vão impactar diretamente, primeiro, a vida das mulheres pobres e negras. Uma segunda questão é sobre os corpos das mulheres e as formas de perversão, de perversidade desse sistema. Às vezes, a gente fica dizendo que sabe que isso aqui vai superar, que a gente vai sair desse momento fascista e a gente vai dar a volta por cima. Não sabemos quando, mas temos certeza de que vamos superar. Mas a questão é: quantas de nós morrerá? A gente tem certeza de que muita gente vai morrer e muitas mulheres vão sofrer. E quando pega a questão da violência, mesmo da violência urbana que mata os filhos, as mães morrem junto. O que estão se tornando os presídios? Verdadeiros navios negreiros. Sem contar o aumento das mulheres que estão sendo encarceradas por essa política ridícula de droga e tudo mais.

Então, é sempre sobre a vida das mulheres e agora muito mais. A gente sente muito porque nós vamos pagar muito alto por isso, com a nossa própria vida. E nisso aí ninguém está livre: pode ser eu, pode ser minha irmã, pode ser minha sobrinha, pode ser o seu filho, o seu sobrinho que sai na rua, pode ser qualquer um, com essa política louca de armamento e essa legitimidade da violência. Porque o que a gente está vendo é legitimar uma violência que já existia e agora você está legitimado a reagir com arma. Ou mesmo legitimar o pensamento de ódio. Você está legitimado pelos chefes maiores do seu país a manifestar seu ódio, seu pensamento preconceituoso, seu pensamento de ódio. E é tão forte essa legitimação que quando saiu o resultado dessa eleição, teve gente que já começou a sair dando tiro, já começou a dizer: "Agora é Bolsonaro!". Já começou a fazer perversidade, mesmo antes de assumir, ou seja, já se sentiu no poder. E isso é muito perigoso, uma vulnerabilidade social terrível que a gente está vivendo no campo, voltando a fome na cidade, voltando a fome e tudo mais, faltando de tudo, então, uma legitimação de uma violência vai dar o quê? Muita gente vai morrer.

Outra contribuição com que Verônica nos brinda com a entrevista é a reflexão sobre como pensar a construção de um feminismo a partir dos territórios, especialmente os territórios rurais. Para ela, diferente de um feminismo rural como identidade, o feminismo no rural é a expressão de uma práxis feminista produzida no e com o território. Essa dimensão é uma importante contribuição para pensar os "novos" olhares sobre uma práxis e uma epistemologia feminista a partir de territórios periféricos. Por fim, destacamos que a entrevista respeitou a linguagem coloquial e expressões utilizadas pela entrevistada, não sendo alteradas em sua transcrição e na construção do texto.

\section{Referências}

ARAÚJO, Gabriela Monteiro. "MEDO NÓS TEM, MAS NÃO USA": narrativas feministas rurais do Movimento da Mulher Trabalhadora Rural do Nordeste (MMTR-NE). 2019. Mestrado (Núcleo de Estudos Interdisciplinares sobre a Mulher - NEIM/FFCH). Universidade Federal da Bahia, Salvador, BA, Brasil.

BLOG DA MARCHA MUNDIAL DAS MULHERES. O que é a Marcha Mundial das Mulheres. Disponível em https://marchamulheres.wordpress.com/mmm/. Acesso em 08/07/2020.

\footnotetext{
${ }^{11}$ Mantivemos o termo conforme verbalizado por Verônica.
} 
CÁRITAS BRASILERIA REGIONAL NORDESTE 3. "Sem Medo de Ser Mulher", YouTube, 13/11/2018. Disponível em https://www.youtube.com/watch?v=XjJRA_mEjol. Acesso em 18/1 1/2020.

MOVIMENTO DE MULHERES TRABALHADORAS RURAIS DO NORDESTE - MMTR-NE (Site Oficial). Disponível em http://www.mmtrne.org.br/nossa-historia-e-nosso-fazer.php. Acesso em 08/07/2020.

MOREIRA, Sarah Luiza de Souza. A contribuição da Marcha das Margaridas na construção das políticas públicas de agroecologia no Brasil. 2019. Mestrado (Programa de Pós-Graduação em Meio Ambiente e Desenvolvimento Rural) - Universidade de Brasília, Brasília, DF, Brasil.

MULHERES RURAIS EM MOVIMENTO. Codireçao: Héloïse Prévost e MMTR-NE (França-Brasil). YouTube. Caruaru, 2016. Disponível em https://www.youtube.com/watch?v=PQkIWTlyJc4.

SOS CORPO - INSTITUTO FEMINISTA PARA A DEMOCRACIA (Site Oficial). Disponível em https:ll soscorpo.orgl. Acesso em 18/1 1/2020.

VIEIRA, Iasmim de Araujo. "A Estrada da Sabedoria": A produção de conhecimento no interior do Movimento da Mulher Trabalhadora Rural do Nordeste. 2017. Mestrado (Programa de PósGraduação em Sociologia) - Universidade Estadual de Campinas, Campinas, SP, Brasil.

Raquel Oliveira Lindôso (raquel.lindoso@yahoo.com.br) é doutoranda em Ciências Sociais (IFCH/UNICAMP). Realizou estágio doutoral na equipe Genre, Travail, Mobilités (GTM) do Centre de Recherches Sociologiques et Politiques de Paris (CRESPPA/CNRS). Coorganizou os dossiês "Aventura Coletiva: a influência de Danièle Kergoat e Helena Hirata nos estudos do trabalho e na luta feminista no Brasil", Revista Trabalho \& Política (53a edição, 2020), e "A mulher na sociedade de classe 50 anos depois: a atualidade de Heleieth Saffioti", Revista Lutas Sociais (vol. 23, n० 43, 2019).

Elaine Mauricio Bezerra (elainemauriciobezerra@gmail.com) é doutora em Ciências Sociais pela Universidade Estadual de Campinas, com período sanduíche no Programa Universitario de Estudios de Género (PUEG) da Universidad Nacional Autónoma de México (UNAM). É membro do grupo de pesquisa Trabalho, Desenvolvimento e Políticas Públicas da Universidade Federal de Campina Grande e do Núcleo de Estudos Heleieth Saffioti: gênero, sexualidades, feminismos, da Universidade Federal de São Paulo. É coorganizadora do Dossiê: "Heleieth Saffioti - 50 anos d'A Mulher na Sociedade de Classes", publicado na Revista Estudos Feministas (v. 29, n. 1, 2021). 


\section{COMO CITAR ESTE ARTICO DE ACORDO COM AS NORMAS DA REVISTA}

LINDÔSO, Raquel Oliveira; BEZERRA, Elaine Mauricio. "Trilhas e saberes compartilhados: o feminismo no rural por Verônica de Santana". Revista Estudos Feministas, Florianópolis, v. 29, n. 3, e76726, 2021.

\section{CONTRIBUIÇĀO DE AUTORIA}

Raquel Oliveira Lindôso: Contribuiu na confecção do roteiro de entrevista, bem como para sua realização análise dos resultados e trabalho de edição e redação da entrevista.

Elaine Mauricio Bezerra: Contribuiu na elaboração do roteiro da entrevista, na análise das informações, na redação da entrevista e na edição final.

\section{FINANCIAMENTO}

Não se aplica.

\section{CONSENTIMENTO DE USO DE IMAGEM}

Não se aplica.

\section{APROVAÇĀO DE COMITÊ de ÉTICA EM PESQUISA}

Não se aplica.

\section{CONFLITO DE INTERESSES}

Não se aplica.

\section{LICENÇA DE USO}

Este artigo está licenciado sob a Licença Creative Commons CC-BY 4.0 International. Com essa licença você pode compartilhar, adaptar, criar para qualquer fim, desde que atribua a autoria da obra.

\section{HISTÓRICO}

Recebido em 26/08/2020

Reapresentado em 18/1 1/2020

Aprovado em 27/1 1/2020 